\title{
Role of Magnetic Resonance Imaging in the Assessment of Perianal Fistulas
}

\author{
H.A. Al-Khawaria R. Gupta ${ }^{a}$ T.S. Sinan ${ }^{a} \quad$ B. Prakash ${ }^{b}$ A. Al-Amer ${ }^{b}$ \\ S. Al-Bolushic
}

${ }^{a}$ Department of Radiology, Faculty of Medicine, Kuwait University, and bepartments of Surgery and ${ }^{\mathrm{c}}$ Radiology, Al-Amiri Hospital, Kuwait

\section{Key Words}

Magnetic resonance imaging • Perianal fistula •

Perineum $\cdot$ Perianal abscess
MRI showed accurate correlation with surgical findings and aided in preoperative management and planning for surgery.

Copyright $@ 2005$ S. Karger AG, Basel

\begin{abstract}
Objective: This study was carried out to evaluate the role of magnetic resonance imaging (MRI) in preoperative assessment of fistula-in-ano. Subjects and Methods: Twenty-six patients (21 male and 5 female, age 19-65 years) were prospectively studied from July 1999 to December 2001 using a 1.0-tesla superconducting magnet. $T_{1}$-weighted fast spin echo ( $T_{1} W$ FSE) images before and after gadolinium injection and fat suppressed $T_{2^{-}}$ weighted fast spin echo ( $\mathrm{T}_{2} \mathrm{~W}$ FSE) images were obtained in transverse and coronal planes. MRI findings were correlated with surgical findings. Results: Twentyone of the 26 patients demonstrated active fistulas. The MRI findings were in accordance with the examination findings under anesthesia and/or surgery in 15 of 16 cases. Both coronal and transverse planes were useful in assessing the location and direction of tracts and abscesses. Both contrast-enhanced $T_{1} W$ FSE and fat-suppressed $\mathrm{T}_{2} \mathrm{~W}$ FSE images were useful in assessing the activity of lesions and the course of tracts. Conclusion:
\end{abstract}

\section{KARGER}

Fax +41613061234

E-Mail karger@karger.ch

www.karger.com
(C) 2005 S. Karger AG, Basel

1011-7571/05/0141-0046\$22.00/0

Accessible online at:

www. karger.com/mpp

\section{Introduction}

Accurate anatomical mapping of fistulas and potential perirectal suppuration, secondary extensions and relationship to the pelvic floor, sphincters and adjacent perirectal structures is of paramount importance for treatment decisions and planning of surgery. Classification of fistulas relates the primary tract to the sphincter complex [1], indicating the likely extent of the sphincter division. For example, the level at which a transsphincteric tract crosses the external sphincter to reach the ischiorectal fossa is variable; the higher the level, the greater the division of the bulk of sphincter below it would be performed. The risk of subsequent incontinence is greatest when treatment of complex fistulas is inappropriately applied [1]. Classification therefore determines management, alerting the surgeon to the need for staged procedures, perhaps using Seton threads, in an attempt to preserve function where necessary as inadequate or inappropriate fistuloto-
Dr. Hanaa Al-Khawari

Department of Radiology, Faculty of Medicine

Kuwait University, PO Box 24923

13110 Safat (Kuwait)

Tel./Fax +965 5330473, E-Mail drhana@yahoo.com 
my can lead to unhealthy ulcers, fecal incontinence and/or need for repetitive complicated surgery [2, 3]. Previously fistulography, proctoscopy and examination under anesthesia (EUA) were the procedures commonly used for the assessment of perianal fistulas. Currently with the use of endoanal ultrasound (EAUS) and magnetic resonance imaging (MRI) and to a lesser extent, computed tomography $(\mathrm{CT})[4,5]$, it is possible to have accurate preoperative assessment of these tracts, especially in highly complicated fistulas, as a necessary prerequisite for a successful surgery. Of all the imaging modalities, MRI has been considered the modality of choice to detect and assess fistula-in-ano because of its three-dimensional imaging capability and higher soft tissue resolution [6-9]. Therefore we evaluated the role of MRI in preoperative assessment of fistula-in-ano.

\section{Subjects and Methods}

A total of 33 MRI scans were performed in 26 patients ( 21 male, 5 female, age range 19-65 years) for prospective evaluation of the presence of fistula-in-ano and perianal abscess at Al-Amiri Hospital, Kuwait, from July 1999 to December 2001. Seven patients underwent follow-up MRI; the time interval was variable, ranging from 2 months to 2 years depending on the clinical condition of the patient. Informed consent was obtained from all the patients prior to the study. Twenty patients clinically presented with recurrent fistula, 2 had perianal discharge for the first time with fistulography suggesting complex fistula and 4 had perianal lump and/or pain without discharge. Three patients had proven Crohn's disease. Of the 26 patients, 9 had fistulography, 16 had EUA with 12 cases undergoing surgical exploration. Twenty-three had proctoscopy performed by the referring surgeon. The combinations of examinations performed in all the patients are shown in table 1.

MRI examinations were performed using a 1.0-tesla superconducting magnet (GE Signa Horizon). Patients were scanned in a supine position using phased array coil (body flex). $\mathrm{T}_{1}$-weighted $\left(\mathrm{T}_{1} \mathrm{~W}\right)$ fast spin echo images (TR 575, TE 20, 3 NEX, ETL 2) were obtained before and after an intravenous injection of $10 \mathrm{ml}$ of gadolinium given by hand. Images were obtained within $1 \mathrm{~min}$ of the injection. $\mathrm{T}_{2}$-weighted $\left(\mathrm{T}_{2} \mathrm{~W}\right)$ fast spin echo images (TR 4500, TE 80, 3 NEX, ETL 10) with fat suppression were obtained in both transverse and coronal planes. Slice thickness was $6 \mathrm{~mm}$ with an interspaced gap of $2 \mathrm{~mm}$; FOV was $25 \times 25$ and the imaging matrix was $256 \times 192$. The slices were planned on a sagittal localizer. The transverse sections were taken at a right angle to the anal canal; the coronal sections were parallel to the canal. The subcutaneous tissue overlying the gluteus maximus was properly covered since perianal complications commonly spread to the subcutaneous tissue. Total scanning time was $40 \mathrm{~min}$. No patient preparation was required. Anal or rectal luminal probes were not used due to its painful insertion and to avoid emptying the abscesses. The examination was well tolerated by all the patients. Each scan was reviewed by 2 radiologists and the results were recorded according to the classification of Parks et al. [1]. The final interpretation was agreed by consensus. Fistulous tracts were differentiated from abscesses by using the criteria of Laniado et al. [6] in which fistulas were defined as being fluid-filled tubular structures with a diameter smaller than $10 \mathrm{~mm}$ and abscesses were larger than $10 \mathrm{~mm}$. Air pockets within the fluid collection also suggested the presence of abscess.

MRI findings were correlated with the surgical results, exploration/probing during general anesthesia, fistulography or proctoscopy, whenever appropriate and were grouped as abscess, active fistula (when enhancement was seen in the tract wall) and inactive fistula (when no enhancement was seen). Internal openings were detected by MRI when the tract connects to anal mucosa.

\section{Results}

\section{MRI Findings}

MRI demonstrated active fistulas in 21 of the 26 patients $(81 \%)$, primary abscess in $4(15 \%)$ and inactive tract in 1 case (4\%) (table 2). Using the classification of Parks et al. [1], the primary tracts were 9 ischiorectal, 7 intersphincteric, 3 transsphincteric, 1 subcutaneous and 1 extrasphincteric. Secondary tracts were seen in 9 patients, secondary abscess whether ischiorectal or pararectal were seen in 11 and supralevatoric extensions in 4 patients. Internal opening was identified in 10 and external opening in 16 of the 26 cases. Of the 16 cases with external opening, 5 were sealed, i.e. covered with skin.

MRI findings were in accordance with findings of EUA and/or surgery in 15 of 16 cases, but in 1 case MRI could not demonstrate the internal opening which was found at surgery. MRI demonstrated simple intersphincteric fistulas with scarred tract proximally in 1 case; the patient was asymptomatic on the day of the MRI study. In 2 cases the MRI scan showed ischiorectal tract with scar tissue proximally. In these 3 cases, the inactive part of the tract was confirmed by EUA.

In 10 cases in which neither EUA nor surgery was performed the findings were correlated with fine-needle aspiration cytology (FNAC) and MRI in 2 cases only. In 1 case MRI showed subcutaneous abscess and this was a chronic organizing inflammation as confirmed by FNAC. The second case was an intersphincteric fistula, which improved clinically by conservative therapy and had a normal follow-up MRI. In the other 8 cases MRI could not be confirmed because 5 cases were still awaiting surgery and 3 were lost to follow-up. In one of the cases lost to followup, MRI depicted a simple intersphincteric tract and failed to demonstrate the fistulous tract connected to the rectum, which was detected by fistulography. This is the only case in the present series where fistulography complemented the MRI findings. 
Table 1. MRI findings in the evaluated 26 cases with follow-up

\begin{tabular}{|c|c|c|c|c|c|}
\hline Case & Age/sex & MRI findings & $\begin{array}{l}\text { MRI FU } \\
\text { time interval }\end{array}$ & $\begin{array}{l}\text { Confirmed } \\
\text { by }\end{array}$ & Remarks \\
\hline 1 & $14 / \mathrm{F}$ & subcutaneous sinus with subcutaneous abscess & - & surgery & $\begin{array}{l}\text { MRI guided the surgeon to the } \\
\text { site of tract }\end{array}$ \\
\hline 2 & $42 / \mathrm{M}$ & primary subcutaneous abscess & - & FNAC & $\begin{array}{l}\text { FNAC showed organizing } \\
\text { inflammation }\end{array}$ \\
\hline 3 & $29 / \mathrm{M}$ & ischiorectal sinus with ischiorectal abscess & 5 months $\mathrm{PO}$ & surgery & FU MRI and FU EUA PO normal \\
\hline 4 & $52 / \mathrm{M}$ & ischiorectal sinus with ischiorectal abscess & - & surgery & \\
\hline 5 & $37 / \mathrm{M}$ & $\begin{array}{l}\text { ischiorectal sinus with levator ani muscle abscess and } \\
\text { secondary ischiorectal sinus tract }\end{array}$ & - & surgery & $\begin{array}{l}\text { levator ani muscle abscess missed } \\
\text { prior to MRI }\end{array}$ \\
\hline 6 & $26 / \mathrm{F}$ & ischiorectal sinus & - & EUA & \\
\hline 7 & $51 / \mathrm{M}$ & ischiorectal inactive tract & 12 months & EUA & $\begin{array}{l}\text { patient had no discharge on day } \\
\text { of MRI, FU MRI normal }\end{array}$ \\
\hline 8 & $22 / \mathrm{F}$ & ischiorectal fistula with secondary ischiorectal tract & - & surgery & \\
\hline 9 & $52 / \mathrm{M}$ & ischiorectal sinus, tract scarred proximally & 2 months & EUA & $\begin{array}{l}\text { patient had no discharge on day } \\
\text { of MRI, FU MRI normal }\end{array}$ \\
\hline 10 & $58 / \mathrm{M}$ & ischiorectal horseshoe tract & - & surgery & internal opening missed by MRI \\
\hline 11 & $60 / \mathrm{M}$ & ischiorectal horseshoe tract with ischiorectal abscess & - & surgery & \\
\hline 12 & $30 / \mathrm{M}$ & primary ischiorectal abscess & - & surgery & \\
\hline 13 & $51 / \mathrm{M}$ & transsphincteric fistula with secondary ischiorectal tract & - & surgery & \\
\hline 14 & $29 / \mathrm{M}$ & $\begin{array}{l}\text { transsphincteric sinus with supralevatoric abscess and } \\
\text { secondary tract extension }\end{array}$ & 3 months PO & surgery & $\begin{array}{l}\text { supralevatoric abscess missed } \\
\text { prior to MRI, FU MRI normal }\end{array}$ \\
\hline 15 & 29/M & intersphincteric fistula with subcutaneous secondary tract & - & surgery & \\
\hline 16 & $26 / \mathrm{M}$ & intersphincteric fistula with secondary horseshoe tract & - & surgery & \\
\hline 17 & $35 / \mathrm{M}$ & simple intersphincteric fistula, tract scarred proximally & - & EUA & $\begin{array}{l}\text { patient had no discharge on day } \\
\text { of MRI }\end{array}$ \\
\hline 18 & $30 / \mathrm{M}$ & intersphincteric fistula with secondary ischiorectal sinus & 17 months & clinically & FU MRI normal \\
\hline 19 & $42 / \mathrm{M}$ & primary subcutaneous abscess & - & not confirmed & awaiting surgery \\
\hline 20 & $65 / \mathrm{M}$ & $\begin{array}{l}\text { ischiorectal sinus with secondary subcutaneous tract and } \\
\text { multiple small subcutaneous abscesses }\end{array}$ & 22 months & not confirmed & $\begin{array}{l}\text { awaiting surgery FU MRI } \\
\text { showed no change }\end{array}$ \\
\hline 21 & $30 / \mathrm{M}$ & primary ischiorectal abscess & - & not confirmed & awaiting surgery \\
\hline 22 & $35 / \mathrm{M}$ & simple intersphincteric sinus multiple subcutaneous abscesses & - & not confirmed & lost to follow-up \\
\hline 23 & $34 / \mathrm{M}$ & simple intersphincteric fistula & - & not confirmed & lost to follow-up \\
\hline 24 & $45 / \mathrm{M}$ & intersphincteric fistula & - & not confirmed & lost to follow-up \\
\hline 25 & $30 / \mathrm{M}$ & uncomplicated transsphincteric sinus with para-anal abscess & 7 months & not confirmed & $\begin{array}{l}\text { awaiting surgery FU MRI } \\
\text { showed no change }\end{array}$ \\
\hline 26 & $19 / \mathrm{F}$ & extrasphincteric sinus with pararectal abscess & - & not confirmed & awaiting surgery \\
\hline
\end{tabular}

$\mathrm{FU}=$ Follow-up $; \mathrm{PO}=$ postoperative.

MRI findings aided the surgeon in planning surgical drainage of a subcutaneous abscess in a 14-year-old girl with Crohn's disease presenting with perianal pain, in which the external opening was not clinically visible. Two cases underwent several surgical drainage procedures before MRI could demonstrate the supralevatoric abscess, which was the cause of failure of previous surgeries. In 3 cases, EUA found no active pathology as confirmed by MRI.

Eight cases had blind-ending sinuses at surgery/EUA; MRI identified sinuses in all 8 cases. There was a good correlation between surgical and MRI findings for the detection of internal openings in 9 of the 10 cases. Six of the 10 cases had fistulas at surgery/EUA, MRI identified 5 of them, in 1 case the internal opening was not identi- fied. MRI showed secondary tract and/or abscesses in 18 cases, all tracts and/or abscesses found at operation had been identified on MRI, no further tracts or abscesses were found at operation that had not been identified on MRI.

Of the 7 cases where MRI follow-up was done within a time interval ranging from 2 months to 2 years (table 2), 2 cases (done postoperatively) did not show active tracts and both were clinically asymptomatic. Another 2 cases did not show any improvement by conservative therapy clinically and no change of the MRI findings, both are waiting for surgery. The remaining 3 cases improved clinically and follow-up MRI did not show active tract (a second EUA confirmed the findings in 2 of them). 
Fig. 1. Transverse $T_{1} W$ image with contrast (a) and transverse fat-suppressed $\mathrm{T}_{2} \mathrm{~W}$ image of a right-sided transsphincteric fistula with internal opening at 6 o'clock position (b).
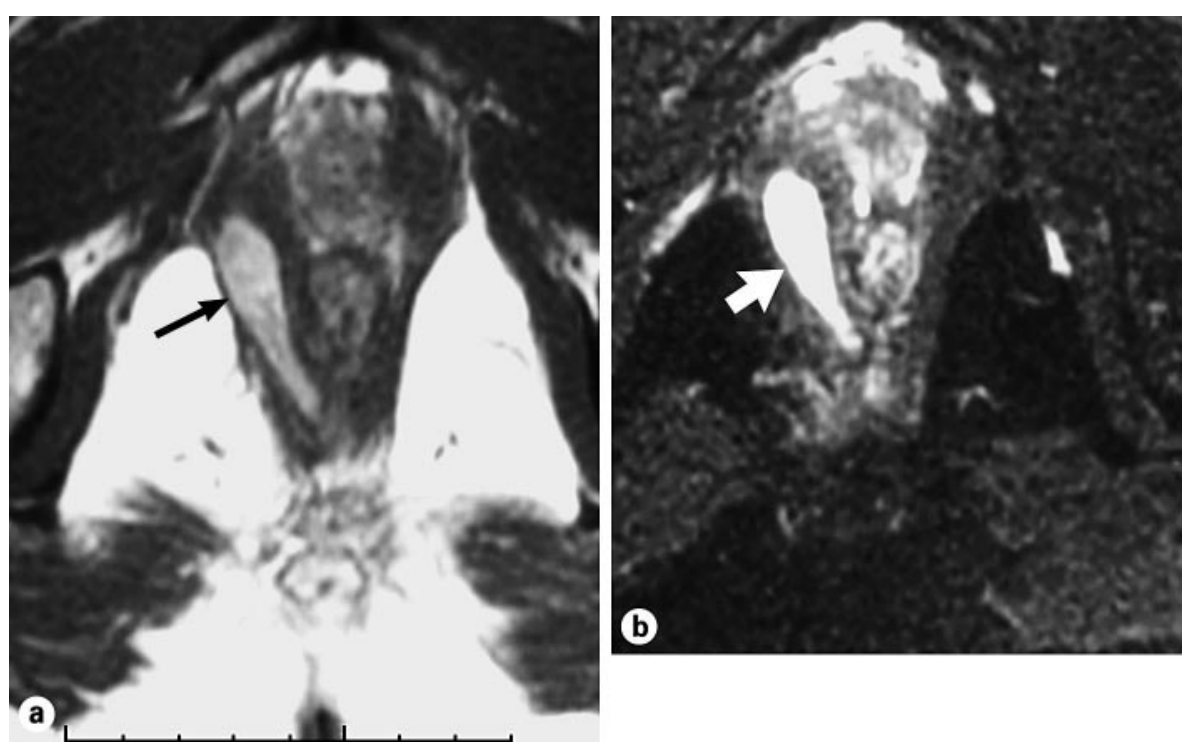

Table 2. Types of examinations performed in the 26 patients

\begin{tabular}{lr}
\hline Clinical examination only & 6 \\
Clinical and fistulography & 3 \\
Clinical and EUA/surgery & 10 \\
Clinical and fistulography and EUA/surgery & 6 \\
Clinical and FNAC & 1 \\
\hline Total & 26 \\
\hline
\end{tabular}

Both coronal and transverse planes were useful in assessing the location and direction of the tracts and the abscesses. On $\mathrm{T}_{1} \mathrm{~W}$ images, both the fistulous tract and the abscess were of low signal intensity and both showed intense enhancement of the wall with contrast, which is a sign of active disease. On fat-suppressed $\mathrm{T}_{2} \mathrm{~W}$ images, tracts and abscesses appeared of high signal intensity against a background of low signal intensity. Healed tracts and postoperative scarring and fibrosis appeared hypointense on both $\mathrm{T}_{1} \mathrm{~W}$ and fat-suppressed $\mathrm{T}_{2} \mathrm{~W}$ images, and did not enhance with contrast. The transverse plane was the best for evaluating the infralevatoric lesions (fig. 1), while the coronal plane was the best for levator ani muscle and supralevatoric lesions (fig. 2a-d, fig. 3a, b, respectively). Horseshoe tracts were best evaluated using the transverse images (fig. 4).

Contrast was useful in assessing the presence of inflammation in the levator ani muscles and in showing the anatomical details of the anal canal and its relations, especial- ly the internal and external sphincter muscles. Both the contrast-enhanced $T_{1} W$ images and fat-suppressed $T_{2} W$ images were useful in assessing the activity and the course of the tract. Although noncontrast $\mathrm{T}_{1} \mathrm{~W}$ images could give good anatomical details, however they could be committed in order to reduce the scanning time.

\section{Discussion}

Before the advent of CT and MRI, perianal fistulas were difficult to evaluate. Surgeons were able to visualize external openings and sometimes internal openings using proctoscopic examinations and probing. Among the imaging techniques, fistulography is the technique most frequently performed for detecting the course of fistulous tracts, assessment of secondary tracts, abscess formation and exact location of internal opening. Fistulography, however, requires probing the fistulous tract and injection of contrast material, making this an invasive and painful procedure. It is also a time-consuming procedure that carries risk of dissemination of infection [10]. Equally important, this procedure often overlooks or underestimates the complete assessment of the fistulous tract. According to previous studies, identification of internal openings by fistulography has been reported in only $24 \%$ of cases and presence of supralevatoric extension was detected in only $56 \%$ of the cases $[11,12]$. Accurate assessment of both internal openings and extensions and detection of supralevatoric extension of a fistulous tract was possible in only 
Fig. 2. Coronal (a) and transverse (b) $\mathrm{T}_{1} \mathrm{~W}$ images with contrast. Coronal (c) and transverse (d) fat-suppressed $\mathrm{T}_{2} \mathrm{~W}$ images of an extrasphincteric fistula crossing the left levator ani muscle and forming a left-sided pararectal abscess with air pocket (note the bright signal in the abscess in $\mathbf{a}$ and $\mathbf{b}$ due to high protein content).

Fig. 3. Coronal $T_{1} W$ images with contrast (a) and coronal fat-suppressed $\mathrm{T}_{2} \mathrm{~W}$ images (b) of left-sided ischiorectal abscess (small arrow) pushing the levator ani upwards (big arrow) but not crossing it.
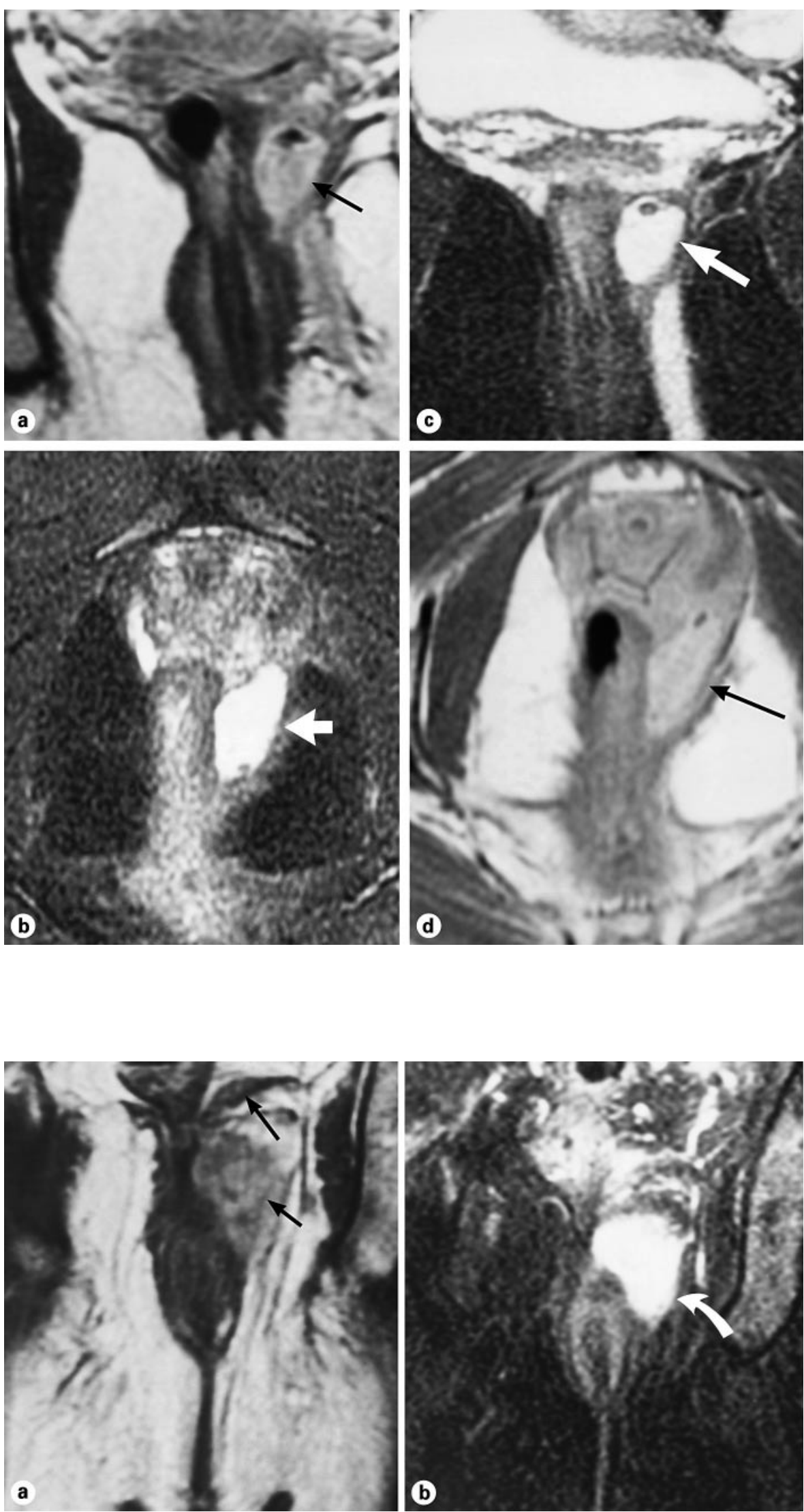


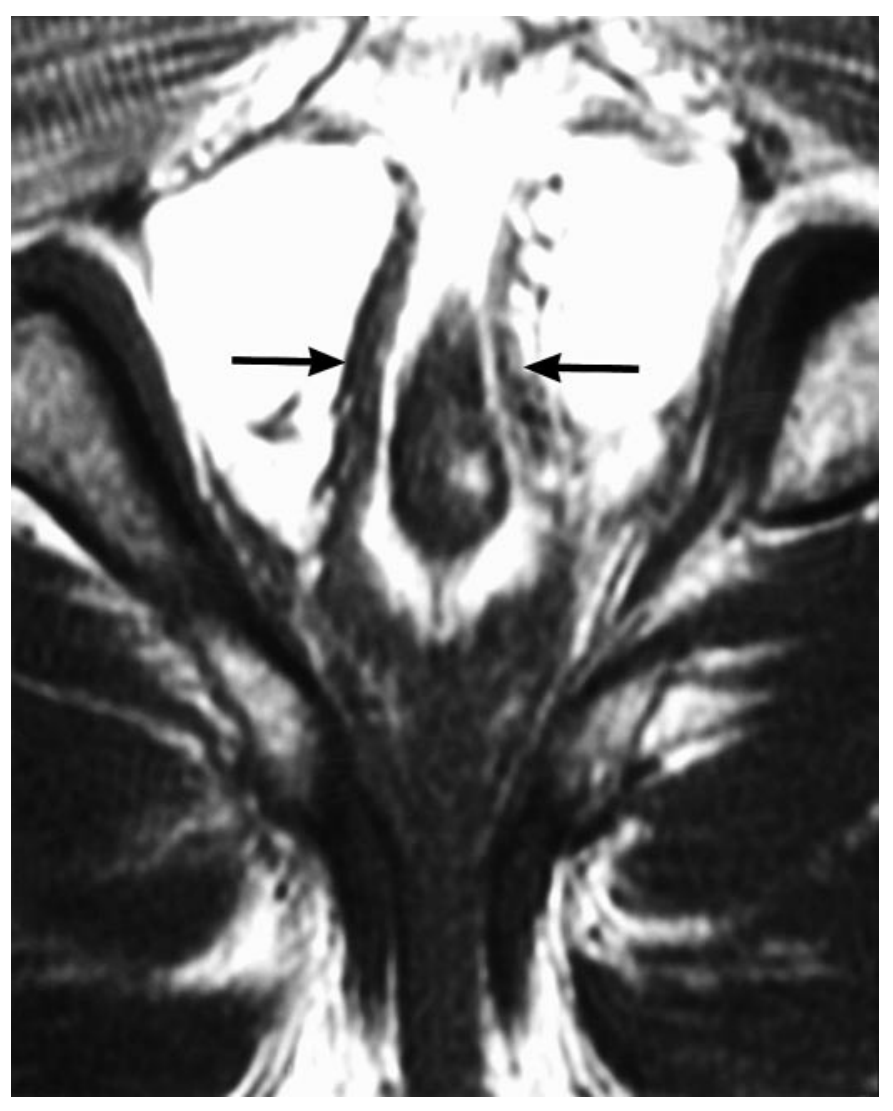

Fig. 4. Transverse $T_{1} W$ image of a horseshoe-shaped ischiorectal tract.

16 and $12 \%$ of the cases, respectively [12], but using MRI both in the present and previous studies [8], MRI could detect $80 \%$ of internal openings, thereby indicating superiority of MRI.

The technique of EAUS, although useful, does not evaluate supralevatoric complications and extrasphincteric tracts due to limited focal range of the rectal probe and lack of definition of the ischiorectal fossa. It is also operator-dependent, thereby limiting the use of this technique. This examination has been reported to be painful and may empty the abscess by compression [7].

CT scan has been reported to be inferior to EAUS in diagnosing fistulas and abscesses in patients with Crohn's disease [13]. CT was not reliable in differentiating between active fistula and fibrotic tissue, and in assessing levator ani muscle and intersphincteric relations. Since the CT images are limited to the transverse plane and coronal imaging of the anorectal region is not satisfactory, the exact type of fistula and the relation to the levator ani muscle cannot be properly examined. With the introduction of multislice CT scanners, the resolution of images, especially the coronal reformation, can be improved in assessing perianal diseases.

MRI has been found to be the investigation of choice and has been shown to be superior to digital exploration, EAUS and CT scan and has been reported to be at least as accurate as surgery in assessing perianal fistulas [6]. It is noninvasive and can be performed on a outpatient basis without anesthesia. The multiplanar imaging capability makes imaging of deeper pathologic anatomic relations possible.

In the present study both $\mathrm{T}_{1} \mathrm{~W}$ images with contrast and fat-suppressed $\mathrm{T}_{2} \mathrm{~W}$ images were useful in detecting the course of the tract as well as identifying associated pathology. $T_{1} \mathrm{~W}$ images with contrast were found to be as good as fat-suppressed $\mathrm{T}_{2} \mathrm{~W}$ images in detecting the pathology and both were needed to delineate the tracts.

The coronal and transverse images were both valuable in assessing the course and the anatomical location of the tracts and abscesses. The transverse images were found to be most useful in identifying infralevatoric tracts and abscesses, while the coronal images were excellent for supralevatoric tracts and abscesses in the levator ani muscles. Inflammation of the levator ani muscles was best seen using coronal $\mathrm{T}_{1} \mathrm{~W}$ images with contrast. In our study, horseshoe tracts were better appreciated and classified using transverse images as reported by others [8].

MRI offers an accurate differentiation between active and inactive anal fistulas and sinuses. The activity of perianal disease could be differentiated from inactive disease on the basis of MRI appearance. Scar tissues and postoperative fibrosis appeared hypointense on $T_{1} W$ and fatsuppressed $\mathrm{T}_{2} \mathrm{~W}$ images and did not show enhancement with contrast. Active lesions appeared as high intensity on fat-suppressed $T_{2} \mathrm{~W}$ images and low intensity with $\mathrm{T}_{1} \mathrm{~W}$ images with intense enhancement post contrast. However, scar tissue has also been reported to be hyperintense on $\mathrm{T}_{2} \mathrm{~W}$ images [6].

During the clinical examination, the surgeon can visualize the external opening and sometimes using proctoscopy can see the internal opening, but knowing the exact location of the internal opening, full assessment of fistulous tract course and secondary complications such as abscess formation and secondary tracts are needed prior to surgical intervention. In our study, MRI was valuable in assessing these conditions similar to previous reports $[7,8]$, thereby aided the surgeon in knowing its direction and facilitated probing of the tracts, thus avoiding creation of false tracts or false internal openings. Recent stud- 
ies have demonstrated a good correlation between surgical and MRI findings in identifying the internal opening [14]. In our study, among the surgically operated cases $(\mathrm{n}=10)$ diagnosed as having fistulas/sinuses MRI could demonstrate internal openings in 4 of $5(80 \%)$ surgically proven cases consistent with a previous report of 28 of 35 $(80 \%)$ patients [8]. In the remaining 5 of the 10 cases of this study, neither MRI nor surgery demonstrated internal opening.

\section{Conclusion}

The results indicate that MRI showed accurate correlation with surgical findings and aided in preoperative planning/treatment.

\section{References}

1 Parks AG, Gordon PH, Hardcastle D: A classification of fistula-in-ano. Br J Surg 1976;63:112.

$>2$ Allan A, Keighley MR: Management of perianal Crohn's disease. World J Surg 1988;12: 198-202.

3 Van Beers B, Grandin C, Katheuser A, Hoang P, Mahieu P, Detry R, Vanheuverzwijn R, Pringot J: MRI of complicated anal fistulae: Comparison with digital examination. Comput Assist Tomogr 1994;18:94-99.

$\checkmark 4$ Halligan S: Imaging fistula-in-ano. Clin Radiol 1998;53:85-95.

$\checkmark 5$ Garcia-Aguilar J, Belmonte C, Wong D, Goldberg SM, Madoff RD: Anal fistula surgery: Factors associated with recurrence and incontinence. Dis Colon Rectum 1996;39:723-729.
Laniado M, Makowiec F, Dammann F, Jehle EC, Claussen D, Starlinger M: Perianal complications of Crohn's disease: MR imaging findings. Eur Radiol 1997;7:1035-1042.

7 Lunniss PJ, Barker PG, Sultan AH, Armstrong P, Reznek RH, Bartram CI, Cottam KS, Phillips RK: Magnetic resonance imaging of fistula-in ano. Dis Colon Rectum 1994;37:708718.

8 Barker PG, Lunniss PJ, Armstrong P, Reznek RH, Cottam K, Phillips RK: Magnetic resonance imaging of fistula-in-ano: Technique, interpretation and accuracy. Clin Radiol 1994; 49:7-13.

9 Perini L, Marcon M, Bidoli L, Fabris G, Ferraro B, Cavallo A, Zacchi C: Magnetic resonance imaging in the assessment of perianal fistula. Radiol Med (Torino) 1995;89:637-642.

$>10$ Tio TL, Muder CJJ, Wijers OB, Sars PR, Tytgat GN: Endosonography of peri-anal and pericolorectal fistula and/or abscess in Crohn's disease. Gastrointest Endosc 1990;36:331-336.
Weisman RI, Orsay CP, Pearl RK, Abcarian H: The role of fistulography in fistula-in-ano: Report of five cases. Dis Colon Rectum 1991;34: 181-184.

12 Kujipers HC, Schulpen T: Fistulography for fistula-in-ano: Is it useful? Dis Colon Rectum 1985;28:103-104.

13 Schratter-Sehn AU, Lochs $\mathrm{H}$, Vogelsang $\mathrm{H}$, Schurawitzki H, Herold C, Schratter M: Endoscopic ultrasonography versus computed tomography in the differential diagnosis of perianorectal complications in Crohn's disease. Endoscopy 1993;25:582-586.

14 Chapple KS, Spencer JA, Windsor CJ, Wilson D, Ward J, Ambrose NS: Prognostic value of magnetic resonance imaging in the management of fistula-in-ano. Dis Colon Rectum 2000;43:511-516. 